\title{
LA PRIMACÍA DE LA PERSECUCIÓN PENAL: REFLEXIONES SOBRE LA PRISIÓN PREVENTIVA TRAS LAS MODIFICACIONES INTRODUCIDAS AL CÓDIGO PROCESAL PENAL POR LA LEY 20.253 ("AGENDA CORTA ANTIDELINCUENCIA")
}

\author{
EDISON ORELLANA* \\ Universidad de Chile
}

\begin{abstract}
RESUMEN: La ley 20.253, también denominada Agenda corta antidelincuencia, modificó sustancialmente el Código Procesal Penal, en cuanto las nuevas normas privilegian la persecución penal por sobre las garantías individuales, contrariando así los principios orientadores originales de dicho cuerpo legal. Se analiza aquí el alcance de dichas modificaciones respecto de la prisión preventiva y, además, se evalúa críticamente esta reforma legislativa a partir de una perspectiva dogmática garantista de la Constitución Política de la República y los Tratados Internacionales sobre Derechos Humanos.
\end{abstract}

Palabras clave: Persecución penal, garantias individuales, Estado de Derecho, Código Procesal Penal.

ABSTRACT: The 20.253 act, also named Brief anti-criminal agenda, substantially modified the Code of Criminal Procedure, as the new rules favour criminal prosecution over individual guarantees, contradicting in this way the guiding principles of this legal body. Analyzed here is the outreach of such modifications regarding preventive prison and, also, a critical evaluation from a dogmatic perspective that is guarantor of the Constitution and International Treaties on Human Rights is given.

Key words: Penal prosecution, individual guarantees, Rule of Law, Code of Criminal Procedure.

La Reforma Procesal Penal, sin duda alguna, significó un vuelco radical en la tramitación de las causas penales en Chile. Vino a sustituir un procedimiento de carácter inquisitivo (señalado así por el propio mensaje del Código de Procedimiento Penal, el mismo establecido desde la edad media), escrito, secreto y en que era la misma persona la que investigaba, acusaba y dictaba sentencia. En definitiva, el antiguo procedimiento penal daba cuenta "de una lógica preliberal en la cual el poder del Estado se ejerce de modo prácticamente absoluto respecto del imputado, quien quedaba sometido casi por completo frente a los órganos de la persecución en una condición de extrema vulnerabilidad ${ }^{1}$, lo cual trataba de compensarse a través de un rígido control judicial de las resoluciones más importantes del proceso por parte de los tribunales jerárquicamente superiores. En cambio, el nuevo proceso penal tiene una orientación acusatoria, es de carácter oral, público y en él las funciones jurisdiccionales e investigativas se encuentran radicadas en órganos diferentes.

Sin embargo, la ley 20.253, denominada Agenda Corta Antidelincuencia, dictada en marzo de 2008, por razones que parcialmente se revisarán más adelante, ha venido a

\footnotetext{
* Ayudante ad honorem de las cátedras de Filosofía (de la) Moral e Historia de la Filosofía del Derecho en la Facultad de Derecho de la Universidad de Chile.

${ }^{1}$ Riego, Cristián. Informe Nacional de Chile, en Maier, Julio, Ambos, Kai y WoischniK, Jan. Las reformas procesales penales en América Latina. Buenos Aires: Ed. Ad-Hoc, , 200. p. 168.
} 
modificar sustancialmente el nuevo Código Procesal Penal, pasando a ser una verdadera reforma de la reforma. El presente trabajo pretende ofrecer una perspectiva general del alcance de esta modificación legal, centrándose específicamente en los impactos de esta en la medida cautelar personal denominada prisión preventiva y, para estos efectos, se divide en cuatro secciones. En la primera sección se explica brevemente cómo funcionaba la prisión preventiva en el antiguo proceso penal, con el objeto de explicar la evolución de las respectivas normas y principios. En la segunda parte se explican los principios orientadores (originarios) del Código Procesal Penal en materia de medidas cautelares, y en especial, de las medidas cautelares personales, y también una reseña del fundamento de tales principios. En la tercera sección se analizan posibles interpretaciones de las modificaciones introducidas por la Agenda Corta Antidelincuencia en materia de prisión preventiva y se evalúa críticamente el cambio legal ya señalado a partir de una interpretación sistemática de normas constitucionales y de tratados internacionales de derechos humanos suscritos por Chile. Por último, se esbozan en la cuarta sección algunas conclusiones.

1.

El antiguo procedimiento penal tenía tres etapas: el sumario, el plenario y la fase de sentencia. En la primera etapa, que era secreta, el juez del crimen, al menos formalmente, realizaba la investigación ayudado por la policía. Concluida esta, debía decidir si acusaba al imputado (si lo sometía a proceso), y en caso de que esto ocurriera debía señalar la existencia de antecedentes que hicieren presumir fundadamente la participación del imputado en el delito investigado. Dictada dicha resolución (el auto de procesamiento), un efecto automático de ella era la prisión preventiva del imputado tratándose de crímenes y simples delitos. Prisión preventiva, para propósitos de este trabajo, es "la medida cautelar que consiste en la privación de la libertad ambulatoria de una persona, mediante su ingreso a un centro penitenciario, durante la sustanciación de un proceso penal y con el objeto de asegurar los fines del procedimiento" 2 .

Por otra parte, aun cuando el juez podía dejar en libertad al imputado una vez que lo sometía a proceso, esto implicaba necesariamente que este quedaba con arraigo nacional y con la obligación de comparecer periódicamente a reportarse al tribunal. Sin embargo, en los hechos estas medidas eran excepcionales, siendo la prisión preventiva la regla general, y no teniendo esta una limitación temporal. En otras palabras, en el antiguo procedimiento penal no se concebía (ni en la teoría ni en la práctica) la posibilidad de que un procesado quedase sin alguna medida cautelar personal, y además, establecía la medida cautelar personal más lesiva de la libertad individual, esto es, la prisión preventiva, a la aplastante mayoría de los casos. Evidentemente, esta situación vulneraba las normas y principios del debido proceso establecidas tanto en la Constitución Política de la República como en los Tratados Internacionales de Derechos Humanos suscritos por Chile, en especial aquellas reglas que establecen la presunción de inocencia de los imputados hasta

2 Moreno Catena, V. et al. El nuevo proceso penal. Estudios sobre la Ley Orgánica 7/ 1988. Valencia: Tirant lo Blanch, 1989. p. 524. 
que una sentencia judicial declare lo contrario ${ }^{3}$. En efecto, dado que una consecuencia práctica de la presunción de inocencia es la excepcionalidad de la prisión preventiva, esta solo opera una vez que se admite que dicha medida cautelar es indispensable en algunos casos para una administración de justicia eficiente ${ }^{4}$.

Además, desde una perspectiva sistemática del antiguo procedimiento penal, vale la pena destacar que el rol de la prisión preventiva, en la práctica, era mucho mayor que el de simplemente asegurar la presencia del imputado o el peligro de fuga. En efecto, otro de los problemas en el proceso penal antes de la reforma era la lentitud, siendo una de las causas la ausencia (al menos, en la ley) de selectividad en la persecución penal, de modo que cada caso debía pasar por las mismas etapas independientemente de la gravedad del delito, lo que obviamente condujo a que los juzgados del crimen y los juzgados con competencia común tendieran a colapsar ante el exceso de causas que debían tramitar. En consecuencia, dada la inevitable lentitud del sistema, el sometimiento a proceso del imputado con su consiguiente prisión preventiva era percibido socialmente como el verdadero castigo al delito supuestamente cometido. En el mismo sentido, parte importante de los jueces generalmente entendían la prisión preventiva como una respuesta a la criminalidad frente a las demandas ciudadanas por el control de esta última. En la práctica, estos factores se tradujeron en que durante los últimos años de vigencia del antiguo procedimiento penal chileno más de la mitad de la población carcelaria se encontraba en prisión preventiva y no condenada por una sentencia firme.

En resumen, las situaciones más relevantes del proceso penal antiguo respecto del tema de este trabajo, son: 1) la ausencia casi absoluta de medidas cautelares alternativas a la prisión preventiva; 2) la prisión preventiva como regla generalísima en caso de que el imputado fuese sometido a proceso; 3) la ausencia (en la ley) de limitación temporal para esta medida cautelar; 4) la evidente contradicción, respecto de las medidas cautelares personales, entre, por un lado, las normas del Código de Procedimiento Penal y, del otro, las normas de de la Constitución Política y los tratados internacionales sobre Derechos Humanos y; 5) la percepción judicial y social de que la prisión preventiva era el medio idóneo para sancionar los delitos y combatir la delincuencia.

2.

La reforma procesal penal, en materia de medidas cautelares, significó una verdadera revolución, en cuanto pretendía otorgar prioridad a los derechos individuales de los ciudadanos. Sin embargo, no hizo otra cosa que dar coherencia al ordenamiento jurídico chileno en materia procesal penal (superando el problema '4' planteado en la sección anterior) puesto que el nuevo Código se limitó a tomar como principios orientadores las

\footnotetext{
${ }^{3}$ Artículos $5^{\circ}$ inciso 2o, 19 № 3 y 19 No 7 letras d) y e) de la Constitución Política de la República; y artículos 7.5 y 8.2 de la Convención Americana de Derechos Humanos (Pacto de San José de Costa Rica) y artículos 9.3 y 14.2 del Pacto de Derechos Civiles y Políticos.

${ }^{4}$ En el mismo sentido, respecto del carácter necesario de la prisión preventiva en algunas hipótesis, véase RoxiN, Klaus. Derecho Procesal Penal. Buenos Aires: Editores del Puerto, 2000, p. 257
} 
disposiciones respectivas de la Constitución Política y los tratados internacionales de Derechos Humanos y los consagró expresamente. En efecto, el nuevo Código Procesal Penal estableció, en primer lugar la presunción de inocencia del imputado (art. 4º), la interpretación restrictiva de las normas del Código que autoricen la restricción de la libertad o de otros derechos del imputado (art. 50), y la excepcionalidad de la prisión preventiva (art. 139), estableciendo una serie de medidas cautelares alternativas a esta, tanto personales como reales. Por último, las medidas cautelares pasaron a operar exclusivamente a petición de los Fiscales del Ministerio Público, en la medida que estos acrediten el cumplimiento de los requisitos legales.

Ahora bien, respecto de la oportunidad procesal, el Código permitía (y permite aún) solicitar la prisión preventiva en la audiencia de formalización de la investigación (o en cualquier etapa de esta si ya se hubiere formalizado), en la audiencia de preparación del juicio oral o en la audiencia de juicio oral. Sin embargo, hasta hoy lo usual en la práctica es que en la mayoría de los casos se realice en una misma audiencia la formalización de la investigación y la discusión acerca de las medidas cautelares. Además, el nuevo Código estableció garantías adicionales respecto de las circunstancias que deben verificarse para siquiera poder discutir la procedencia de la prisión preventiva: se requiere necesariamente la presencia del imputado y de su defensor.

Por otro lado, la reforma procesal penal impuso limitaciones temporales a la prisión preventiva (art. 145) y estableció los siguientes requisitos para su procedencia (art. 140): a) La existencia de antecedentes que justifiquen la existencia del delito que se investiga ${ }^{5}$; b) la existencia de antecedentes que permitieren presumir fundadamente que el imputado ha participado en el delito y; c) la existencia de antecedentes calificados que permitan considerar que la prisión preventiva es indispensable para el éxito de determinadas diligencias de la investigación, o que la libertad del imputado fuere peligrosa para la seguridad de la sociedad o del ofendido. Dentro de este esquema, el Código entregaba (y aún hoy entrega) al intérprete ciertas pautas orientadoras para determinar en qué casos la libertad del imputado implica peligrosidad para la sociedad o para el ofendido (como la existencia de procesos pendientes en contra del imputado, por ejemplo). Como puede apreciarse, lo planteado en el art. 140 letra c) apunta a la necesidad de cautela y/o peligro de retardo (periculum in mora), aunque ciertamente la doctrina más garantista se ha opuesto a la causal de "peligrosidad para la seguridad de la sociedad" señalando que esta finalidad de la prisión preventiva no satisface fines procesales, sino penales (esto es, que operaría directamente como sanción sin juicio previo). Por ejemplo, el procesalista italiano Luigi Ferrajoli señala que dicho criterio implica "hacer recaer sobre el imputado una presunción de peligrosidad basada únicamente en la sospecha del delito cometido [puesto que aún no ha habido un juicio donde se pruebe que se cumplen los requisitos que hacen proceder la responsabilidad penal], equivale de hecho a una presunción de culpabilidad (énfasis añadido)" 6 . Esta crítica parece razonable en cuanto pone de manifiesto el hecho de que en esta

\footnotetext{
${ }^{5}$ Ha habido alguna discusión respecto de cómo debe entenderse el término delito. En esto parece más razonable interpretarlo como "hecho típico, antijurídico y culpable" y no meramente como un hecho "típico", que solo configura una apariencia de delito.

${ }^{6}$ Ferrajoli, Luigi. Derecho y Razón. Teoría del garantismo penal. Madrid: Editorial Trotta, 1995, p. 553.
} 
hipótesis la prisión preventiva deja de ser una medida cautelar y se convierte en un instrumento de control social, en una pena sin juicio previo o en una presunción de responsabilidad penal. Por otro lado, como lo hacen notar los profesores Julián López y María Inés Horvitz, sobre este asunto existe una evidente antinomia entre la regulación constitucional y las disposiciones respectivas del Pacto de Derechos Civiles y Políticos y la Convención Americana de Derechos Humanos, que en opinión de ellos debe solucionarse entendiendo que la disposición del art. 19 No 7 letra e), que permite la prisión preventiva por esta causal, está tácitamente derogada 7 . Lo cierto es que en la práctica se ha entendido por los Fiscales del Ministerio Público y por la mayoría de los tribunales que "peligro para la seguridad de la sociedad" es equivalente a "peligro de reincidencia”, priorizando así el tenor literal del texto constitucional en desmedro del claro sentido de las reglas sobre prisión preventiva contenidas en los ya mencionados Tratados de Derechos Humanos ${ }^{8}$.

La nueva regulación implicó una disminución ostensible en la utilización de la prisión preventiva, siendo la causal más invocada el peligro para la seguridad de la sociedad ${ }^{9}$. Sin embargo, "en este sentido, la discusión sobre necesidad de cautela no parece haberse concretizado lo suficiente al caso particular. Las razones para decretar la prisión preventiva por peligro para la sociedad siguen siendo en una medida importante relativamente abstractas, independiente de los elementos concretos del caso particular" ${ }^{10}$. Por lo tanto, no es de extrañar que en los hechos, una vez acreditada la participación, la existencia del delito y que la pena que conllevara el delito fuera superior a 5 años y un día, los tribunales se vieran compelidos a dictar la prisión preventiva ${ }^{11}$.

El efecto principal que estas modificaciones legales tuvieron en la percepción de la ciudadanía y de la prensa fue generar una sensación de impunidad. En efecto, si legalmente (y en la práctica) la prisión preventiva pasó de ser la regla general a ser la excepción, y si hasta entonces la prisión preventiva era, de hecho, el verdadero castigo, era un tanto obvio que de inmediato surgirían voces (que, de hecho surgieron) exigiendo mano dura (queriendo decir más imputados en prisión preventiva), evocando así la mentalidad inquisitiva que inspiraba al procedimiento antiguo. Aparentemente se generó entre la ciudadanía "una cierta percepción de que la reforma sería más blanda en su tratamiento del delito y menos eficaz para resolver casos" 12 , puesto que las salidas alternativas, la disminución del uso de la prisión preventiva y la disminución de las facultades de los funcionarios policiales se entendieron (y se entienden aún) como equivalentes a la impunidad.

Ahora bien, en lo que respecta a los fundamentos de los principios orientadores del nuevo Código, vale la pena detenerse en al menos dos de ellos: la presunción de inocencia

\footnotetext{
7 Horvitz, María Inés, y López, Julián. Derecho Procesal Penal Chileno. Tomo I. Santiago: Editorial Jurídica de Chile, 2002, pp. 413- 414.

${ }^{8}$ Una interpretación más garantista la ofrece Juan Carlos Marín, quien sostiene que "peligro para la seguridad de la sociedad" es equivalente a "peligro de fuga", por lo que no se encuadrarían en esta norma los supuestos de "peligro de reincidencia”. Al respecto véase MARín, Juan Carlos. Las medidas cautelares en el nuevo proceso penal chileno (Apuntes de Diplomado). Santiago: Centro de Estudios de la Justicia, Facultad de Derecho, Universidad de Chile, 2001, p. 30.

9 Baytelman, Andrés (redactor). Evaluación de la Reforma Procesal Penal Chilena. Santiago: Centro de Estudios de la Justicia, Escuela de Derecho, Universidad de Chile, 2002, p. 97

${ }^{10}$ Ibid.

11 Ibid.

12 Baytelman, Andrés, op. cit. (n. 9), p. 99.
} 
y la excepcionalidad de la prisión preventiva. Estos se encuentran estrechamente vinculados, siendo el segundo de ellos una aplicación específica (respecto de las medidas cautelares) o una consecuencia práctica del primero.

La presunción de inocencia, consagrada en los tratados internacionales de derechos humanos vigentes en Chile, parte del supuesto que la única manera de determinar si respecto de un individuo corresponde aplicar una pena privativa de libertad es una sentencia dictada por un tribunal imparcial, con posterioridad a un juicio. En consecuencia, mientras no haya juicio, la persona debe ser tratada como inocente, puesto que no existe certeza jurídica de que el imputado haya cometido un hecho típico, antijurídico y culpable. Como resulta casi obvio, este principio entra necesariamente en conflicto con la existencia de la medida cautelar de la prisión preventiva ${ }^{13}$. Respecto de este punto, la mayoría de la doctrina procesal penal, sin embargo, ha evitado ubicarse en alguno de los polos de este debate y ha centrado la discusión en el análisis de los fines de la prisión preventiva, entendiendo que la posibilidad de coexistencia entre este instituto y la presunción de inocencia está condicionada por los fines que se reconozcan al primero ${ }^{14}$. Para estos efectos, existe algún grado de consenso respecto de que "los fines de la prisión preventiva solo pueden ser fines de aseguramiento del procedimiento y de la ejecución" 15 .

Por otro lado, para quienes son legos en derecho o para quienes no dan prioridad, en la práctica, a los derechos civiles (cuyo fundamento es precisamente limitar el poder de los organismos estatales para proteger a la ciudadanía de una eventual arbitrariedad ellos), resulta difícil de entender el principio de presunción de inocencia, en particular si alguna vez han sido personalmente víctimas de la delincuencia. Sin embargo, existe una vía relativamente sencilla para explicarlo. Este principio contempla la posibilidad de que por circunstancias accidentales una persona totalmente inocente se vea envuelta en un delito (por ejemplo, por un parecido físico a la persona que realmente lo hizo) o en un hecho de apariencia delictual, o que por pura casualidad o arbitrariedad de alguna persona particular o funcionario policial se vea acusada de haber participado en un ilícito penal. Precisamente para este tipo de casos se demuestra el real valor de las garantías procesales del imputado. En un proceso de carácter secreto e inquisitivo, y en que es una misma persona la que investiga, acusa y juzga, una persona acusada de un delito en circunstancias como las señaladas tendría un alta probabilidad de ser sometida a maltratos, prisión preventiva, e incluso condena. En otras palabras, un proceso penal que contempla la presunción de inocencia de imputado hasta que una sentencia ejecutoriada declare lo contrario, se pone en el peor de los casos, esto es, que se acuse de haber cometido un delito a una persona inocente, estableciendo garantías concretas que permitan que esa persona no sea condenada ni que vea restringida innecesariamente su libertad personal durante el tiempo que dure la investigación. Ante esta explicación, pudieran objetar algunos que el delincuente común, esto es, el individuo que tiene un nutrido prontuario de condenas o de procesos pendien-

\footnotetext{
13 Sobre este punto hay dos polos en la doctrina. Algunos señalan que es tal la incompatibilidad entre la presunción de inocencia y la prisión preventiva que debe descartarse la primera. Otros, en cambio, comparten el diagnóstico de la incompatibilidad, pero sostienen que lo que debe eliminarse es la prisión preventiva y no la presunción de inocencia.

${ }^{14}$ Horvitz, María Inés, y LóPEZ, Julián, op.cit. (n. 7), p.391.

${ }^{15}$ HASSEMER, Winfred. Crítica al Derecho Penal de hoy: norma, interpretación, procedimiento, limites a la prisión preventiva. Buenos Aires: Ed. Ad- Hoc, , 1998, p. 119.
} 
tes en su contra, no merece tales garantías. Sin embargo, ante tal objeción existen al menos dos argumentos: 1) La Constitución Política de la República y los Tratados Internacionales de Derechos Humanos suscritos por Chile establecen la igualdad ante la ley, prohibiendo las discriminaciones arbitrarias. Luego, establecer un proceso diferenciado con menos garantías procesales para cierto tipo de personas en atención a su conducta anterior sería una discriminación arbitraria, ya que su conducta no afecta el goce de las garantías procesales de otras personas, y en consecuencia un procedimiento de tales características sería inconstitucional; y 2) Existe un principio de derecho penal sustantivo denominado Non bis in idem, cuya aplicación procesal implica que no se puede juzgar dos veces a una persona por el mismo hecho. Por lo tanto, si una persona ya fue condenada por un delito, no puede considerarse ese factor para darle un tratamiento diferenciado, puesto que esa persona ya pagó su deuda con la sociedad cumpliendo la condena.

Por otro lado, la justificación estándar de la excepcionalidad de la prisión preventiva es como sigue: el Estado chileno derogó, hace algunos años, la pena de muerte, y por ende, en virtud de la obligación impuesta por la norma contenida en el artículo 4.3 de la Convención Americana de Derechos Humanos, no puede restablecer la pena capital. En consecuencia, no pudiendo, el Estado arrebatar la vida a los ciudadanos al menos en la aplastante mayoría de los $\operatorname{casos}^{16}$, el máximo castigo que puede causarles es la privación de libertad. Luego, dada la gravedad de ese castigo, este debe aplicarse en circunstancias muy específicas, a saber: después de un juicio en que haya garantías de imparcialidad del tribunal y (sobre todo) de defensa del acusado, y en que se haya dictado sentencia condenatoria. De ello se sigue que la privación de libertad sin juicio previo debe ser, en el peor de los casos, una excepción, puesto que no ha habido una oportunidad para que el imputado haya ejercido eficazmente su derecho a la defensa, en el sentido de que un letrado haya podido invocar a favor del acusado todos los argumentos de fondo (causales de atipicidad, causales de antijuridicidad, atenuantes o razones referentes a las etapas de desarrollo del delito) y que haya podido rendir las pruebas para los hechos que sirven de base a tales argumentos ${ }^{17} \mathrm{y}$, por otro lado, porque la prisión preventiva "involucra una forma de afectación al derecho a la libertad personal (encarcelamiento) que no logra distinguirse de la que produce la pena privativa de libertad. En otras palabras, desde la perspectiva de la libertad ambulatoria del afectado, pareciera no existir ninguna diferencia entre la prisión preventiva y la prisión punitiva" 18 .

En consecuencia, la medida cautelar de prisión preventiva debe ser, desde esta perspectiva, necesariamente excepcional, dado que no se cumplen los mencionados requisitos del debido proceso que justifican la vulneración más lesiva (de las legalmente posibles) de los derechos de un ciudadano o ciudadana. En este sentido, no entender la prisión

\footnotetext{
${ }^{16}$ La pena de muerte está vigente en Chile respecto de algunos delitos en tiempos de guerra, regulados en el Código de Justicia Militar.

17 Como se explicará posteriormente, una de las diferencias sustanciales, desde una perspectiva garantista, entre una audiencia de discusión de cautelares y un juicio oral, es la posibilidad de rendir pruebas en este último. Respecto a la posibilidad de esgrimir argumentos de fondo, al menos algunos de ellos sí pueden invocarse en la audiencia en que se discute la prisión preventiva (por ejemplo, la existencia de una causal de justificación, para atacar el cumplimiento del requisito de existencia del delito).

${ }^{18}$ Horvitz, María Inés, y LÓPEZ, Julián, op. cit. (n. 7), pp. 389- 390.
} 
preventiva como algo excepcional, y por ende, no defender la presunción de inocencia, "le quita valor al procedimiento principal [el juicio oral] y eleva los resultados del procedimiento instructorio, provisionales y adquiridos con instrumentos jurídicamente menos idóneos, a la categoría de sentencia condenatoria" 19 .

Por lo tanto, puesto que es el juicio oral el medio apto para establecer si se cumplen o no los presupuestos legales que justifican una condena, "de ello se sigue necesariamente que la prisión preventiva no puede perseguir objetivos de derecho penal material. La persecución de fines de prevención general o especial presupone que se encuentre firme el presupuesto de ese derecho penal material: la culpabilidad del afectado" 20 .

Por otro lado, y en términos algo más generales, se puede afirmar que el nuevo Código implicó un cambio en el entendimiento de lo que debe ser la administración de justicia penal. Para estos efectos resulta útil lo planteado por Mirjan Damaska, quien propone un modelo de análisis en que existen dos elementos (polos) que están en constante tensión: de un lado, la persecución penal, y del otro, las garantías individuales, denominando a un Estado que prioriza la primera un Estado activo, y Estado reactivo a uno que prioriza las segundas ${ }^{21}$. Según este modelo, en la medida en que se prioriza la persecución penal (o, si se quiere, una solución represiva a la delincuencia), por ejemplo, aumentando las facultades de los funcionarios policiales, necesariamente se disminuyen o coartan los derechos individuales de los ciudadanos. A contrario sensu, si se priorizan los derechos individuales se cede un tanto en materia de persecución penal (como ocurre, por ejemplo, disminuyendo las facultades de los funcionarios policiales). Esto es así por la evidente incompatibilidad entre los dos elementos. Además, en este mismo sentido, "el orden interno de un Estado se revela en el modo en que está regulada esa situación de conflicto [derechos individuales v/s persecución penal]: los estados totalitarios, bajo la antítesis errónea Estado-ciudadano exagerarán fácilmente la importancia del interés estatal en la realización, lo más eficaz posible, del procedimiento penal. En un Estado de Derecho, en cambio, la regulación de esa situación de conflicto no es determinada a través de la antítesis Estado-ciudadano; el Estado mismo está obligado por ambos fines -aseguramiento del orden a través de la persecución penal y protección de la esfera de libertad del ciudadano-" 22 . En efecto, "la forma en que los estados resuelven la contradicción entre [por ejemplo] presunción de inocencia y prisión preventiva, está en directa relación con los grados de libertad individual que se reconocen en una determinada sociedad" 23 .

El modelo de Damaska muestra un tipo de conflicto análogo que suele producirse entre dos de los valores en juego en este asunto, a saber, la eficiencia y la justicia. La eficiencia quiere decir aquí que un sistema penal funcione en el sentido de castigar la mayor cantidad posible de los delitos denunciados o que ingresan al sistema por otra vía. Desde esta perspectiva, por ejemplo, se dice que, en general, la justicia o el sistema penal

\footnotetext{
${ }^{19}$ HASSEMER, Winfred, op. cit. (n. 15), p. 118.

${ }^{20}$ Ibid.

21 Damaska, Mirjan. Las Caras de la Justicia y el poder del Estado (trad. Andrea Morales Vidal). Santiago: Editorial Jurídica de Chile, 2000, pp. 125- 168.

22 Roxin, Klaus, op. cit. (n. 4), p. 258.

${ }^{23}$ Horvitz, María Inés, y López, Julián, op. cit. (n. 7), p. 392.
} 
estadounidense son eficientes. Y la justicia apunta al hecho de no condenar ni someter a prisión preventiva a personas que no han cometido ningún delito. Por lo tanto, en la medida en que un gobierno decide priorizar la persecución penal y, por ende, la eficiencia del sistema penal, asume el riesgo de que el sistema se vuelva injusto, esto es, que se condene o se envíe a prisión preventiva a personas inocentes. En efecto, el establecimiento de normas legales que facilitan enormemente la labor de los fiscales para efectos de obtener la prisión preventiva de los imputados, aumenta enormemente la posibilidad de que ciudadanos que no han cometido ningún delito y que solo accidentalmente se han visto envueltos en una situación de apariencia delictual sean enviados a la cárcel mientras dura la investigación o incluso hasta que finalice el procedimiento.

En este mismo sentido cabe señalar también que la prisión preventiva, e incluso la mera formalización, tienen un grave efecto desocializador respecto de los imputados. Dado que el ciudadano medio por lo general ignora la lógica del nuevo sistema procesal penal, la formalización de la investigación y la prisión preventiva son percibidas como un juicio definitivo e irreversible de culpabilidad respecto de los imputados. En otros términos, la ciudadanía, por regla general, tiende a creer que si formalizan a alguien, y más aún si lo dejan en prisión preventiva, esa persona es necesariamente responsable y merecedora de todo el rigor de la sanción penal.

3.

La ley 20.253 introdujo una serie de cambios sustantivos al Código Procesal Penal, destinados principalmente a reprimir la actividad delictiva. Respecto de la prisión preventiva, en mi opinión, realizó dos modificaciones relevantes.

La primera de ellas se relaciona con una de las pautas que da el Código Procesal Penal al intérprete para efectos de determinar los casos en que la libertad del imputado resulta peligrosa para la seguridad de la sociedad. La Agenda Corta Antidelincuencia agregó una nueva pauta en este sentido, señalando que "se entenderá especialmente que la libertad del imputado constituye un peligro para la seguridad de la sociedad, cuando los delitos imputados tengan asignada pena de crimen en la ley que los consagra" (art. 140, letra c), inciso 40).

Antes de explicar las posibilidades y problemas de interpretación del texto recién citado, vale la pena aclarar el procedimiento previo a la formalización de la investigación de un delito y en qué consiste esta, dado que al hablarse de delitos imputados se quiere decir delitos por los cuales se haya formalizado la investigación.

Como es sabido, en un momento determinado de la investigación el Fiscal debe decidir si formaliza o no (esto es, si comunica o no al imputado, en presencia del juez de garantía, que se está realizando una investigación en su contra respecto de uno o más delitos determinados), principalmente en base a si cuenta o no con antecedentes suficientes. Se trata de una decisión estratégica, puesto que el Fiscal no está obligado a formalizar la investigación, salvo que requiriera la intervención judicial para la práctica de diligencias investigativas, la recepción anticipada de prueba, la resolución sobre medidas cautelares, o si el imputado estuviere detenido, caso en el cual, la actuación deberá ser llevada a cabo en 
Edison Orellana / La primacía de la persecución penal...

la primera audiencia judicial de este (salvo que el juez acceda a una ampliación de la detención, en cuyo caso tiene 3 días más para formalizar).

Ahora bien, cuando el Fiscal decide formalizar, debe cumplir un estándar relativamente bajo, puesto que solo debe individualizar al imputado, indicar el delito, la fecha y lugar de su comisión, y el grado de participación del imputado en el mismo. Como puede apreciarse, con esto existe la posibilidad de hecho que, intencionalmente o no, se formalice a alguien inocente, incluso por delitos graves. En otras palabras, la ley no impide que un Fiscal formalice a cualquier persona y por cualquier delito, siempre que se cumplan los requisitos mencionados, lo cual se ve reforzado por el hecho de que una vez concluida la investigación puede ejercer la facultad de no perseverar (art. 248 del Código Procesal Penal), con lo que la formalización queda sin efecto. Sin embargo, el Código establece una serie de incentivos para evitar una formalización arbitraria ${ }^{24}$. En primer término, el imputado puede reclamar ante las autoridades del Ministerio Público. En segundo término, el Fiscal no puede acusar a personas o por hechos distintos a los señalados en la formalización, de modo que una formalización negligente o arbitraria le impediría efectuar una acusación con posibilidades razonables de ganar en el juicio oral. Y en tercer lugar, en caso de que el Fiscal desee solicitar medidas cautelares, deberá señalar antecedentes precisos que hagan presumir la existencia del delito y la participación en este del imputado, de modo que si bien el estándar de exigencia es relativamente bajo en la formalización (lo cual permitiría al menos como posibilidad de hecho una formalización arbitraria o negligente) el estándar exigido es bastante mayor al momento de solicitar medidas cautelares, de modo que en caso de que el Fiscal no cumpla con ese estándar mayor la prisión preventiva debiera ser denegada por el juez de garantía respectivo. Sin embargo, este nivel de exigencia mayor jamás alcanza lo que es posible obtener a través de un juicio oral, puesto que en la audiencia de discusión de medidas cautelares no se pueden rendir pruebas (solo puede hacerse referencia a antecedentes de la carpeta de investigación), mientras que la rendición de pruebas define al procedimiento principal ${ }^{25}$.

Hecha esta aclaración, corresponde abordar los problemas interpretativos que plantea el texto citado. Aclarado ya lo que quiere decirse con delitos imputados, la tarea se reduce a determinar el sentido de la expresión "tengan asignada pena de crimen en la ley que los consagra". De acuerdo al Código Penal la pena de crimen es la que es superior a 5 años (5 años y un día o más). Entonces el problema se reduce a determinar el significado de la oscura expresión "tengan asignada (...) en la ley que los consagra". Aquí existen al menos dos posibilidades. La primera de ellas asume que la norma se refiere a la pena que asigna el Código Penal u otra ley especial, en abstracto, esto es, sin aplicar las reglas de determinación de la pena (agravantes, atenuantes, y de fases de desarrollo del delito) establecidas en el Código Penal. En efecto, el tenor literal (“asignada en la ley”) parece apuntar en esta dirección. Además, la redacción de la norma (“se entenderá especialmente”) parece indicar

\footnotetext{
${ }^{24}$ Además, es preciso señalar a este respecto que el ciudadano medio percibe la formalización de la investigación como una verdadera declaración de culpabilidad, por lo que el perjuicio de una formalización negligente o arbitraria puede ser devastador desde un punto de vista social.

25 De hecho, es por eso que el juicio abreviado (donde no se rinde prueba sobre los hechos) no constituye un procedimiento principal dado que existe acuerdo entre las partes acerca de los hechos, mas no respecto de la calificación jurídica.
} 
que se trata de una presunción legal de peligrosidad para la seguridad de la sociedad en caso de que el delito imputado tenga una pena superior a cinco años, lo que se traduce en una inversión de la carga de la prueba, pues en este caso correspondería al defensor demostrar que pese a la pena asignada al delito el imputado no representa un peligro para la seguridad de la sociedad, lo cual facilita bastante la tarea de los fiscales para obtener que se decrete la prisión preventiva de los imputados. Esta interpretación parece ser acorde a la intención de los legisladores, puesta de manifiesto en el mensaje y en la historia de la ley 20.253.

Sin embargo, si se interpreta así la norma ocurre que el cumplimiento del requisito de que la libertad sea peligrosa para la sociedad sería un mero trámite, en cuanto a que si el Fiscal formalizó por un delito que tiene pena superior a cinco años en abstracto, bastaría con invocar en la audiencia respectiva la norma en cuestión para dar por establecido que la libertad del imputado es necesariamente un peligro para la seguridad de la sociedad (salvo que el defensor logre destruir la presunción).

Para ilustrar la gravedad de esta situación, supóngase un caso que el Fiscal ha formalizado por robo con intimidación simple, cuya pena mínima "asignada en la ley que lo consagra” es de cinco años y un día, esto es, pena de crimen. Digamos que los antecedentes con que cuenta para convencer al juez de que cabe presumir la existencia del delito y la participación del imputado son la declaración de la víctima y la de un testigo, que dicen haber reconocido en el imputado al autor del delito. Como el Código exige solo "antecedentes", esto es, solo más de un hecho que apunte en esa dirección (como podrían ser una declaración ante Carabineros, una fotografía, o un informe de criminalística de peritos de la Policía de Investigaciones), y no pruebas que acrediten la existencia del delito y la participación del imputado en este, y como se formalizó por un delito cuya pena mínima es superior a cinco años, el juez no tendría más remedio que decretar la prisión preventiva. Esto es especialmente grave porque el estándar de los "antecedentes" no es lo suficientemente alto, de modo que interpretar así la norma implica que la labor de los fiscales en esta materia se facilita enormemente. La consecuencia de todo esto es que basta la formalización por un delito que tenga asignada en la ley pena de crimen, para que la prisión preventiva vuelva a convertirse en la regla general.

Además, cabe destacar que existe una regla en el Código Procesal Penal que prescribe que las disposiciones que autoricen la restricción de la libertad del imputado deben ser interpretadas restrictivamente y no se podrán aplicar por analogía (art. $5^{\circ}$ inciso $2^{\circ}$ ), lo cual implica una consagración legal del principio in dubio pro reo en materia de medidas cautelares dentro del proceso penal. En consecuencia, la interpretación analizada en el párrafo precedente contradice lo prescrito por la regla citada, en cuanto aumenta considerablemente la probabilidad de que el juez pueda imponerle al imputado la medida cautelar personal que más vulnera la libertad ambulatoria de este. En otras palabras, dicha interpretación no sería sistemática, esto es, que no considera otras normas y principios presentes en el sistema que regulan la misma materia.

Una segunda posibilidad interpretativa sería considerar que la expresión "tengan asignada pena de crimen en la ley que los consagra" significa entender "en la ley" como "en el ordenamiento jurídico", esto es, que si una vez aplicadas las reglas de determinación de la pena esta última es mayor a 5 años de presidio, entonces el imputado debe ser 
considerado un peligro para la seguridad de la sociedad. Esta opción tiene la ventaja de no violentar lo dispuesto por la ya mencionada norma del artículo 5, porque, efectivamente, cumple con lo que ella dispone al interpretar de manera restrictiva una disposición destinada a restringir la libertad del imputado. Además, esta interpretación tiene la ventaja de ser más coherente con la excepcionalidad de la prisión preventiva consagrada en la Constitución y en los Tratados Internacionales de Derechos Humanos, en cuanto la interpretación alternativa necesariamente implica un incremento en la aplicación de la prisión preventiva. No obstante, incluso siguiendo este planteamiento sigue en pie la presunción legal de peligrosidad para la seguridad de la sociedad, de modo que si la pena en concreto supera los cinco años, entonces el imputado será igualmente sometido a prisión preventiva en la medida que el Fiscal logre demostrar que se cumplen también los requisitos de las letras a) y b) del artículo 140 del Código Procesal Penal.

Pasando a otro punto, la segunda modificación relevante de la ley 20.253 respecto de la prisión preventiva es aquella que permite apelar la resolución que rechaza la solicitud de esta medida cautelar impidiendo que el imputado sea puesto en libertad hasta que la sentencia se encuentre ejecutoriada, esto es, hasta que se haya fallado el recurso de apelación y notificado este fallo a las partes, siempre que el imputado haya sido puesto a disposición del tribunal en calidad de detenido. En otras palabras, esta nueva normativa permite que se produzca una curiosa paradoja: si el juez rechaza la solicitud de prisión preventiva y el Fiscal apela, jel imputado queda detenido mientras se resuelve la apelación! Entonces, la decisión del juez de garantía sobre la procedencia de la prisión preventiva pasa a ser casi completamente irrelevante, dado que si es acogida o rechazada el efecto será el mismo: un ciudadano o ciudadana inocente quedará privado de libertad (ya que podemos asumir que el Fiscal apelará cada vez que se rechace su solicitud), siendo la única diferencia la duración de dicha privación. En otros términos, el imputado queda privado de libertad por el simple hecho de que el Fiscal deduzca un recurso de apelación. Esta situación se ve agravada aún más por el hecho de que el imputado queda en una situación procesal indeterminada. No está en prisión preventiva, pero tampoco está libre. Está no puesto en libertad, situación procesal inexistente en la Constitución.

Desde esta perspectiva, dado que el sentido de la norma es claro, no cabe sino hacer un cuestionamiento desde la perspectiva constitucional ${ }^{26}$. En efecto, el artículo 19 No 7 letra e) de la Carta Fundamental exige que exista una resolución judicial para que proceda la privación de libertad, y en la situación planteada por la regla en cuestión ocurre no solo que no hay resolución judicial que justifique la privación de libertad, sino que se contradice la voluntad del único juez que hasta ese momento se ha pronunciado sobre el asunto. A

\footnotetext{
26 En sentencia rol 1001- 2008 de 29 de enero de 2008 el Tribunal Constitucional, mediante control preventivo de constitucionalidad (de carácter abstracto), declaro que la ley 20.253 no era contraria a la Constitución. Sin embargo, respecto del nuevo texto artículo 149 del Código Procesal Penal hubo un voto de minoría de los ministros señores Jorge Correa Sutil y Mario Fernández Baeza, en el sentido de declarar inconstitucional dicho precepto legal. Respecto de las acciones de inaplicabilidad por inconstitucionalidad, hasta ahora los pocos requerimientos presentados han sido rechazados (Ej.: rol 1064-2008, rol 1065-2008, rol 1057-2008, rol 1060-2008, rol 1062-2008) en general por considerar que no existe gestión pendiente porque el recurso de apelación ya ha sido fallado por la Corte de Apelaciones respectiva, o por considerarse que los requerimientos no sugieren un control concreto de constitucionalidad. Un análisis crítico y serio de dichas sentencias merece una extensión que no puedo darle aquí.
} 
esto se suma el hecho de que si la misma Constitución y los Tratados Internacionales de Derechos Humanos establecen la excepcionalidad de la prisión preventiva asumiendo que esta solo procede mediante una resolución judicial fundada ¿qué queda entonces para los casos en que no existe tal resolución, siendo una disposición legal el único fundamento en el caso concreto? Además, la mencionada exigencia constitucional tiene también una consagración expresa en el Código Procesal Penal, que en su artículo 122 prescribe que las medidas cautelares son siempre impuestas por resolución judicial fundada.

Además, vale la pena destacar que, en caso de una acción de inaplicabilidad por inconstitucionalidad, el precepto legal en cuestión siempre será decisivo en la resolución de la gestión pendiente (el proceso penal), en la eventualidad de que se dicte sentencia condenatoria, dado que el artículo 348 del Código Procesal Penal establece que la sentencia condenatoria debe fijar el tiempo de detención o prisión preventiva que deberá servir de abono para su cumplimiento. En otras palabras, el tiempo que el imputado esté no puesto en libertad por encontrarse pendiente la apelación no podrá ser descontado de la pena asignada en la sentencia condenatoria pese a que efectivamente hay privación de libertad, de modo que la norma en cuestión se aplicará cada vez que exista tal sentencia ${ }^{27}$.

En definitiva, parece haber buenas razones para justificar la inconstitucionalidad (en abstracto y en concreto) de la mencionada norma introducida por la ley 20.253, y por cierto esta modificación legal sugiere que pretende priorizarse la persecución penal por sobre las garantías procesales y los derechos individuales por parte de nuestros legisladores. De hecho, la historia de la ley zanja cualquier discusión al respecto.

4.

Corresponde ahora señalar algunas conclusiones respecto de lo abordado en este trabajo.

1.- Hasta antes de la reforma procesal penal la prisión preventiva era la regla general y era percibida por la ciudadanía y por parte importante de los jueces como el verdadero castigo.

2.- Los tratados internacionales de Derechos Humanos vigentes en Chile desde la vuelta a la democracia (Pacto de Derechos Civiles y Políticos y Convención Americana de Derechos Humanos) y la Constitución Política consagran la excepcionalidad de la prisión preventiva. El Código Procesal Penal y los mencionados tratados establecen la presunción de inocencia de los imputados. Estas modificaciones legales implicaron el establecimiento formal de una prioridad de las garantías procesales e individuales de las ciudadanas y ciudadanos.

3.- La prisión preventiva, en su carácter de medida cautelar, no puede cumplir un rol preventivo o sancionador. Dichos roles solo pueden corresponderle una sentencia dictada tras la realización de un juicio. La peligrosidad para la seguridad de la sociedad, entendida como peligro de reincidencia, no es una finalidad aceptable para la prisión preventiva en cuanto constituye una pena sin juicio y una presunción de responsabilidad penal (lo cual está prohibido por la Constitución). No corresponde al proceso penal ni a

27 Este argumento fue sostenido por el profesor Julián López en su calidad de abogado patrocinante de una acción de inaplicabilidad por inconstitucionalidad en la causa rol 1065-2008, que fue rechazada con el voto disidente del Ministro Jorge Correa Sutil. 
los jueces impedir la reincidencia ni combatir la delincuencia, sino solo aplicar las sanciones correspondientes en la medida que se cumplan los requisitos legales de la responsabilidad penal.

4.- Las modificaciones legales introducidas por la ley 20.253 al Código Procesal Penal en materia de prisión preventiva implicaron un cambio de paradigma, en cuanto otorgan prioridad a la persecución penal por sobre los derechos individuales, incluso con la interpretación más garantista de dichas reglas, en cuanto permiten que los fiscales obtengan con mucha mayor facilidad que se decrete la prisión preventiva de los imputados por delitos que tengan pena de crimen.

5.- La modificación que establece un nuevo criterio orientador respecto de cuándo existe peligro para la seguridad de la sociedad implica una presunción legal de tal peligrosidad cuando la pena (en concreto) asignada al delito sea superior a cinco años, lo cual evidentemente aumentará la cantidad de imputados en prisión preventiva en algún recinto penitenciario.

6.- La modificación referente a que el imputado no puede ser puesto en libertad mientras se encuentre pendiente la apelación contra la resolución que rechazó la solicitud de prisión preventiva plantea serios problemas de constitucionalidad, en especial por lo dispuesto en el artículo 19 No 7 letra e) de la Constitución Política de la República.

7.- En definitiva, la ley 20.253 implica un quiebre con los principios rectores originales del Código Procesal Penal, lo cual se traduce en una fuerte restricción de las garantías individuales de los ciudadanos y en un lento retorno al sistema antiguo, que contemplaba a la prisión preventiva como regla general y como un medio eficaz para combatir la delincuencia.

\section{REFERENCIAS BIBLIOGRÁFICAS}

Baytelman, Andrés (redactor). Evaluación de la Reforma Procesal Penal Chilena. Santiago, Centro de Estudios de la Justicia, Escuela de Derecho, Universidad de Chile, 2002.

DAmASKA, Mirjan, Las Caras de la Justicia y el poder del Estado (trad. Andrea Morales Vidal). Santiago, Editorial Jurídica de Chile, 2000.

FERRAJOli, Luigi. Derecho y Razón. Teoría del garantismo penal. Madrid, Editorial Trotta, 1995.

Hassemer, Winfred. Crítica al Derecho Penal de hoy: norma, interpretación, procedimiento, limites a la prisión preventiva. Ed. Ad Hoc, Buenos Aires, 1998.

Horvitz, María Inés, y López, Julián. Derecho Procesal Penal Chileno. Tomo I. Santiago, Editorial Jurídica de Chile, 2002.

MARín, Juan Carlos. Las medidas cautelares en el nuevo proceso penal chileno (Apuntes de Diplomado). Santiago, Centro de Estudios de la Justicia, Facultad de Derecho, Universidad de Chile, 2001.

Moreno Catena, V. et al. El nuevo proceso penal. Estudios sobre la Ley Orgánica 7/ 1988. Valencia, Tirant lo Blanch, 1989.

Riego, Cristian. Informe Nacional de Chile. En MAIER, Julio, Ambos, Kai y WoischniK, Jan. Las reformas procesales penales en América Latina. Ed. Ad-Hoc, Buenos Aires, 2000.

RoXIN, Klaus. Derecho Procesal Penal. Buenos Aires, Editores del Puerto, 2000. 